\title{
Crustal Structure, Seismic Anisotropy and Deformations of the Ediacaran/Cambrian of the Małopolska Block in SE Poland Based on Data from Two Seismic Wide-Angle Experiments
}

\author{
PIOTR ŚRODA ${ }^{1}$
}

\begin{abstract}
The area of SE Poland represents a complex contact of tectonic units of different consolidation age-from the Precambrian East European Craton, through Palaeozoic West European Platform (including Małopolska Block) to Cenozoic Carpathians and Carpathian Foredeep. In order to investigate the anisotropic properties of the upper crust of the Małopolska Block and their relation to tectonic evolution of the area, two seismic datasets were used: seismic wide-angle off-line recordings from POLCRUST-01 deep seismic reflection profile and recordings from active deep seismic experiment CELEBRATION 2000. During acquisition of deep reflection seismic profile POLCRUST-01 in 2010, a 35-km-long line of 14 recorders (PA-14), oriented perpendicularly to the profile, was deployed to record the refractions from the upper crust $(\mathrm{Pg})$ at wide range of azimuths. These data were used for an analysis of the azimuthal anisotropy of the MB with the modified delay-time inversion method. The results of modelling of the off-line refractions from the MB suggest $\sim 6 \%$ HTI anisotropy of the Cambrian/Ediacaran basement, with $\sim 130^{\circ}$ azimuth of the fast velocity axis and mean $V p$ of $4.9 \mathrm{~km} / \mathrm{s}$. To compare this result with previous, independent information about anisotropy at larger depth, a subset of previously modelled data from CELEBRATION 2000 experiment, recorded in the MB area, was also analysed by inversion. The recordings of Pg phase at up to $120 \mathrm{~km}$ offsets were analysed using anisotropic delay-time inversion, providing information down to $\sim 12 \mathrm{~km}$ depth. The CELEBRATION 2000 model shows $\sim 9 \%$ HTI anisotropy with $\sim 126^{\circ}$ orientation of the fast axis. Thus, local-scale anisotropy of this part of MB confirms the large-scale anisotropy suggested by previous studies based on data from a broader area and larger depth interval. The azimuthal anisotropy (i.e. HTI symmetry of the medium) is interpreted as a result of strong compressional deformation during the accretion of terranes to the EEC margin, leading to tight (sub-vertical) folding and fracturing of intrinsically anisotropic metasediments forming the MB basement. Obtained anisotropy models are compared with data about stratal dips of the MB sequences and implications of assuming more realistic TTI model are discussed. Wide-angle recordings from off-line measurements along a reflection profile provided new information about seismic velocity and anisotropy, not available from standard
\end{abstract}

1 Institute of Geophysics, Polish Academy of Sciences, ul. Ks. Janusza 64, 01-452 Warsaw, Poland. E-mail: psroda@igf.edu.pl near-vertical profiling, and contributed to more complete image of the upper crustal structure of Małopolska Block.

Key words: Seismic modelling, crustal anisotropy, refraction seismics, Teisseyre-Tornquist Zone, Małopolska Block.

\section{Introduction}

The area of South-eastern Poland is cut by the Teisseyre-Tornquist Zone (TTZ), representing a contact of major tectonic units of different consolidation age-from the Precambrian East European Craton (EEC), through Palaeozoic West European Platform (WEP) including Łysogóry Block (ŁB) and Małopolska Block (MB), to Cenozoic (Alpine) orogen-the Carpathians (Fig. 1). The lithosphere of this region was built by several phases of crustal accretion of various units at the margin of the EEC, which resulted in a complex collage of tectonic blocks and is, therefore, a natural laboratory for studying the nature of various crust-forming processes.

In the present work, in order to investigate the structure and anisotropic properties of the crust and their relation to tectonic evolution of this area, two seismic datasets were used: seismic wide-angle offline recordings from POLCRUST-01 deep seismic reflection profile, and data from active deep seismic experiment CELEBRATION 2000. The latter experiment consisted of a net of several wide-angle reflection/refraction (WARR) profiles (Guterch et al. 2001). As a result, several 2-D and 3-D models of the crustal and uppermost mantle structure and seismic velocities were published. Modelling of the CELEBRATION 2000 data in SE Poland revealed large 


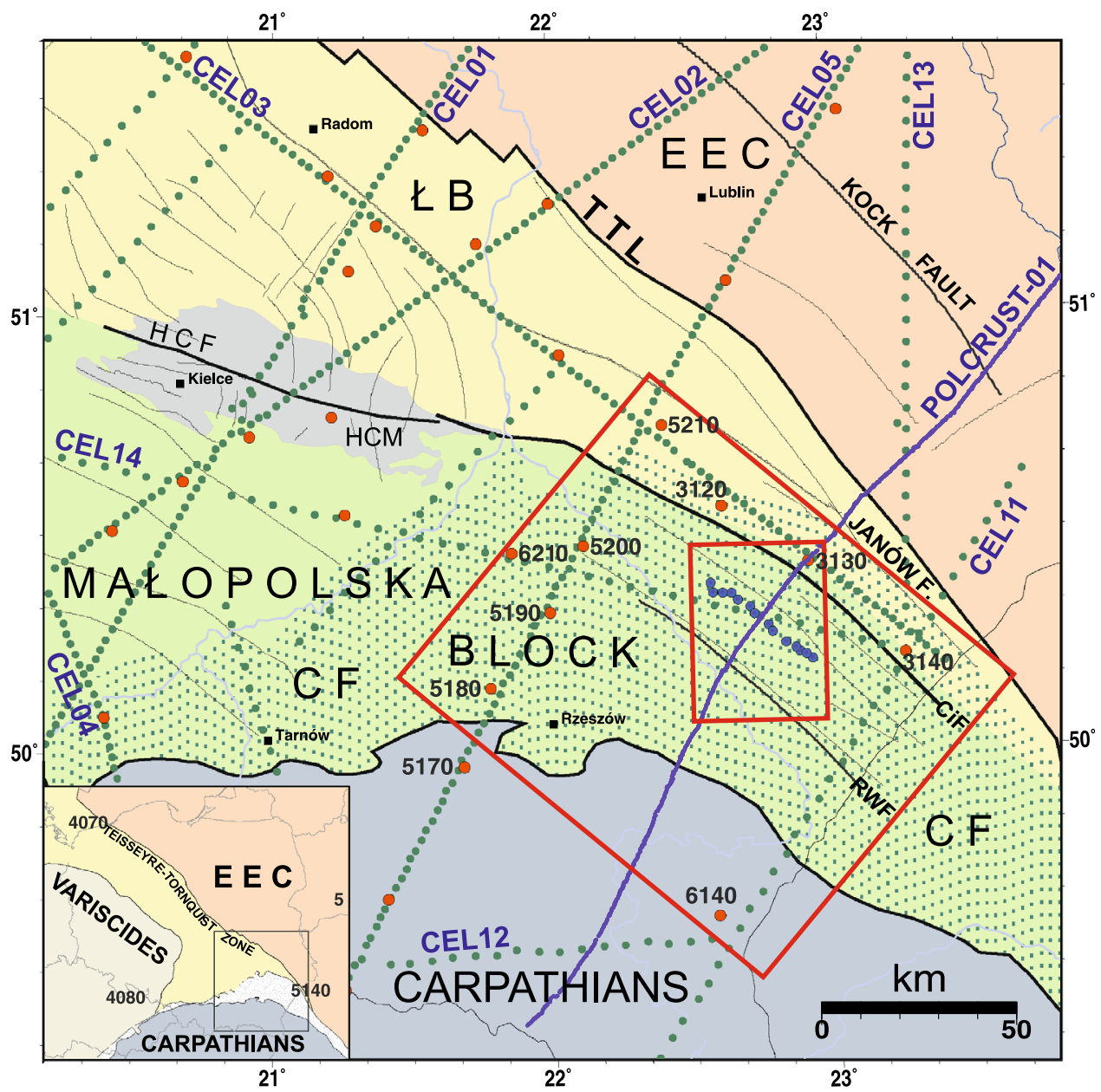

Figure 1

Tectonic sketch of SE Poland with location of POLCRUST-01, PA-14 and CELEBRATION 2000 profiles. Small red rectangle-model area for PA-14 data inversion, large red rectangle - model area for CELEBRATION 2000 data inversion, blue line-POLCRUST-01 profile, blue points-receivers of PA-14 line, red and green points-CELEBRATION 2000 shot points and receivers, respectively, yellow pointslocations of wells providing information about the Cambrian/Ediacaran strata dip discussed in the text, black lines-faults and tectonic boundaries. CF Carpathian Foredeep, CiF Cieszanów Fault, EEC East European Craton, HCF Holy Cross fault, HCM Holy Cross mountains, $Ł B$ Łysogóry Block, $M B$ Małopolska Block, $R W F$ Ryszkowa Wola Fault, TTL Teisseyre-Tornquist Line

azimuthal variations of the apparent velocity of the crustal refracted arrivals $(\mathrm{Pg})$, observed consistently all over a large area of MB and $€ B$. The analysis of this variability using anisotropic traveltime inversion revealed substantial ( $\sim 8$ to $10 \%$ ) azimuthal anisotropy with fast velocity axis direction consistent with trend of main deformational structures in this area (Środa 2006).

Recently, a 240-km-long, deep reflection seismic profile POLCRUST-01 was acquired in 2010 across the contact of EEC, $\mathrm{EB}, \mathrm{MB}$ and Carpathians.
It provided high-resolution image of the crustal structure of this complex area, probing the Ediacaran and Phanerozoic sedimentary cover as well as the deep crust down to the Moho discontinuity (Malinowski et al. 2013). As the profile crossed the anisotropic region of $\mathrm{MB}$ and $€ B$, additional seismic stations were deployed in the vicinity of the line, in order to use the POLCRUST-01 seismic sources for collecting new data that could support and complement previous study of the upper crustal anisotropy. Additional deployment involved 14 recorders located 
along a 35-km-long line (PA-14) perpendicular to the main profile, allowing for recordings in a wide azimuthal range. Such a design of the experiment, targeted on wide-angle (refraction) recordings of seismic sources from a near-vertical reflection experiment provided additional, valuable data on the MB structure.

This work describes the analysis of these data by anisotropic delay-time method and presents new information on the azimuthal anisotropy of the Ediacaran to Palaeozoic MB basement. Additionally, to compare this result with independent information about anisotropy at larger depths, a subset of previously modelled data from CELEBRATION 2000 experiment, limited to the MB area, was also analysed. Off-line recordings of Pg phase at up to $120 \mathrm{~km}$ offsets were modelled with the anisotropic delay-time inversion method, providing information about the crustal anisotropy down to $\sim 12 \mathrm{~km}$ depths.

The results of traveltime inversion of both data sets presented in this paper supply new information about the seismic velocities, anisotropy and the structure of the MB, which, placed in broader geological context, improves the understanding of its evolution and of the tectonic processes shaping the lithosphere of this complex region of TTZ. Also, presented approach shows that supplementing a standard reflection profile acquisition with wide-angle, extended offset and off-line recordings can supply additional data on the structure of the sedimentary sequences. Such study provides more detailed information about seismic velocity and its azimuthal variations than available in case of a standard near-vertical profiling and contributes to more complete image of the uppermost crust.

\section{Geology}

The area of SE Poland represents a complex zone consisting of tectonic units of different consolidation age. The first-order units involve the Precambrian East European Craton and Palaeozoic West European Platform (WEP), with contact along the TeisseyreTornquist Zone-a prominent fault zone between crustal domains of different structure (Fig. 1). The WEP, extending to the SW of the TTZ, is composed of the Łysogóry and Małopolska Blocks, mostly interpreted as Caledonian (late Early Palaeozoic) terranes (see discussion below), separated by the NW-SE trending Holy Cross Fault. In the study area, according to Narkiewicz et al. (2015) the boundary between the $\mathrm{MB}$ and $\mathrm{LB}$ runs along the Cieszanów Fault (CiF). The Ediacaran/Palaeozoic strata of $Ł B$ and MB (mostly deformed with WNW-ESE direction of folding axes) are largely overlain by a Mesozoic/ Cainozoic cover of variable thickness. In particular, in the SE part of the MB (study area), heavily folded and thrusted Ediacaran/Cambrian low-grade metasediments (largely shales, siltstones and claystones), in places unconformably overlain by less deformed Ordovician rocks (Moryc and Jachowicz 2000), are discordantly covered by $0-2 \mathrm{~km}$ thick undeformed Miocene sequences of the Carpathian Foredeep, and further to the South submerge beneath up to $9 \mathrm{~km}$ thick Outer Carpathian flysch nappes, largely of Cretaceous to Neogene age, thrusted over the MB basement with its Palaeozoic-Neogene cover (Gągała et al. 2012).

The origin of $\mathrm{MB}$ and $\mathrm{\iota B}$, as well as their relationship to the adjacent EEC, is still a subject of controversy. They are considered as separate units based on different stratigraphy and evolution. However, there are contrasting views about their Gondwana versus Baltica provenance, the timing of their possible accretion at the EEC margin and their history of Caledonian and Variscan deformations. Pożaryski (1990) interpreted both units as exotic terranes, forming a Caledonian strike-slip orogen. According to $\mathrm{K}-\mathrm{Ar}$ age studies (Belka 2002), the MB is an exotic, Gondwana-derived terrane, while the origin of the $Ł U$ is enigmatic. Dadlez et al. (1994) proposed the origin of the $\mathrm{EB}$ as a part of the EEC passive margin subject later to the Caledonian deformation and interpreted the $\mathrm{MB}$ as a proximal terrane, detached and re-accreted to Baltica. In some interpretations (Jaworowski and Sikorska 2006; Mizerski 2004) the MB is interpreted as a part of the EEC Cambrian passive margin. Recent studies of Narkiewicz et al. (2015) and Malinowski et al. (2015), based on POLCRUST-01 data interpretation, suggest that the Łysogóry Block crust has characteristics typical for the EEC proximal terrane, while the Małopolska Block is clearly an exotic terrane of 
Gondwanan origin. According to Belka et al. (2002) and Mizerski (2004), the rocks of the MB were affected by the Early Caledonian deformation and, subsequently, by Late Caledonian and Variscan events. In the study area (SE part of the MB) no evidence for Variscan deformation has been found. As postulated by Żelaźniewicz et al. (2009), Ediacaran sequences forming most of this part of the Małopolska Block were heavily folded and weakly metamorphosed during the Cadomian (Late Ediacaran) orogeny. Folded Early Cambrian rocks, overlying part of the Ediacaran, were deformed most likely as a result of Early Caledonian (Sandomirian) deformation in the Late Cambrian.

The crustal thickness, determined from wide-angle seismics, varies from 32 to $35 \mathrm{~km}$ in SW to $\sim 45 \mathrm{~km}$ in the NE, near the EEC margin (Środa et al. 2006; Malinowski et al. 2005; Janik et al. 2009). Seismic wide-angle crustal modelling along CELEBRATION 2000 profiles CEL01 (Środa et al. 2006) CEL02 (Malinowski et al. 2005) and CEL05 (Grad et al. 2006), all oriented in the SW-NE direction (roughly perpendicular to the EEC margin) indicated relatively low upper crustal $V p$ velocities in the MB area $(5.3-5.9 \mathrm{~km} / \mathrm{s})$ down to the depth of $18 \mathrm{~km}$. On the other hand, modelling of the CEL14 profile (Janik et al. 2009), oriented approximately in perpendicular (WSW-ENE) direction and intersecting the abovementioned profiles in the MB area, revealed much higher $V p$ velocities $(6.2-6.4 \mathrm{~km} / \mathrm{s})$ in similar depth range and in similar location. This large (up to $0.9 \mathrm{~km} / \mathrm{s}$ ) $V p$ difference for intersecting profiles could not be due to uncertainty of the modelled velocity, as high quality of the recordings and high ray density in the upper crustal layers assured much lower error bounds. A plausible explanation of such large $V p$ variations for profiles with different orientation is seismic azimuthal anisotropy of the crust. This was the motivation for the study of the MB anisotropy by Środa (2006) and for the present work.

\section{Data Acquisition}

The $\sim 240-\mathrm{km}$-long deep reflection seismic profile POLCRUST-01 was acquired in 2010 across the contact of EEC, MB and Carpathians (Malinowski et al. 2013). The seismic measurements were performed using mostly the Vibroseis technique with $30 \mathrm{~m}$ receiver spacing, $60 \mathrm{~m}$ source spacing and extended recording time (30 s). In places not accessible for Vibroseis trucks, explosives were used ( $\sim 2 \%$ of total number of sources). Additionally, besides the standard near-vertical data acquisition, RefTek-125 "Texan" recorders with $4.5-\mathrm{Hz}$ geophones were deployed along the line at $\sim 1.2 \mathrm{~km}$ spacing at offsets up to $\pm 30 \mathrm{~km}$ from currently operating Vibroseis points in order to obtain common-receiver gathers with an extended offset range. This resulted in seismic sections with offsets up to 20-30 km, significantly more than the range of the reflection spread $(10 \mathrm{~km})$. This allowed to record the wide-angle reflections and refracted waves from the uppermost crust. These data were complementary to the near-vertical recordings, providing more detailed information about seismic velocities.

In the SW, the profile crossed the Ediacaran to Palaeozoic Malopolska Block, overlain by undeformed Miocene sediments of the Carpathian Foredeep (CF). Previous results of modelling of wide-angle data from CELEBRATION 2000 experiment evidenced substantial azimuthal anisotropy of the upper and middle crust of the $\mathrm{MB}$ and $\mathrm{tB}$ over a large $(\sim 300 \times 150 \mathrm{~km})$ area, at depth range of $\sim 0.5$ to $15 \mathrm{~km}$ (Środa 2006). In order to supplement these results with study of the possible anisotropy of the shallowest sequences of the $\mathrm{MB}$, a 35-km-long line of 14 recorders (PA-14), oriented perpendicularly to the main profile was deployed, providing recordings of refractions from the uppermost crust at wide range of azimuths (Fig. 2). These data were used for an analysis of the azimuthal anisotropy of this part of the MB.

When choosing the location of the PA-14 profile, to ensure that the refractions recorded by the PA-14 profile will sample a relatively homogeneous part of the Cambrian/Ediacaran MB basement along the longest possible raypaths, an area with most uniform structure and topography of the basement and minimum thickness of the overlying Miocene Carpathian Foredeep sediments was preferred. The latter allowed to maximize the penetration depth in the studied layer-the MB basement. The thickness of the Miocene cover of the $\mathrm{MB}$ along the main profile varies 


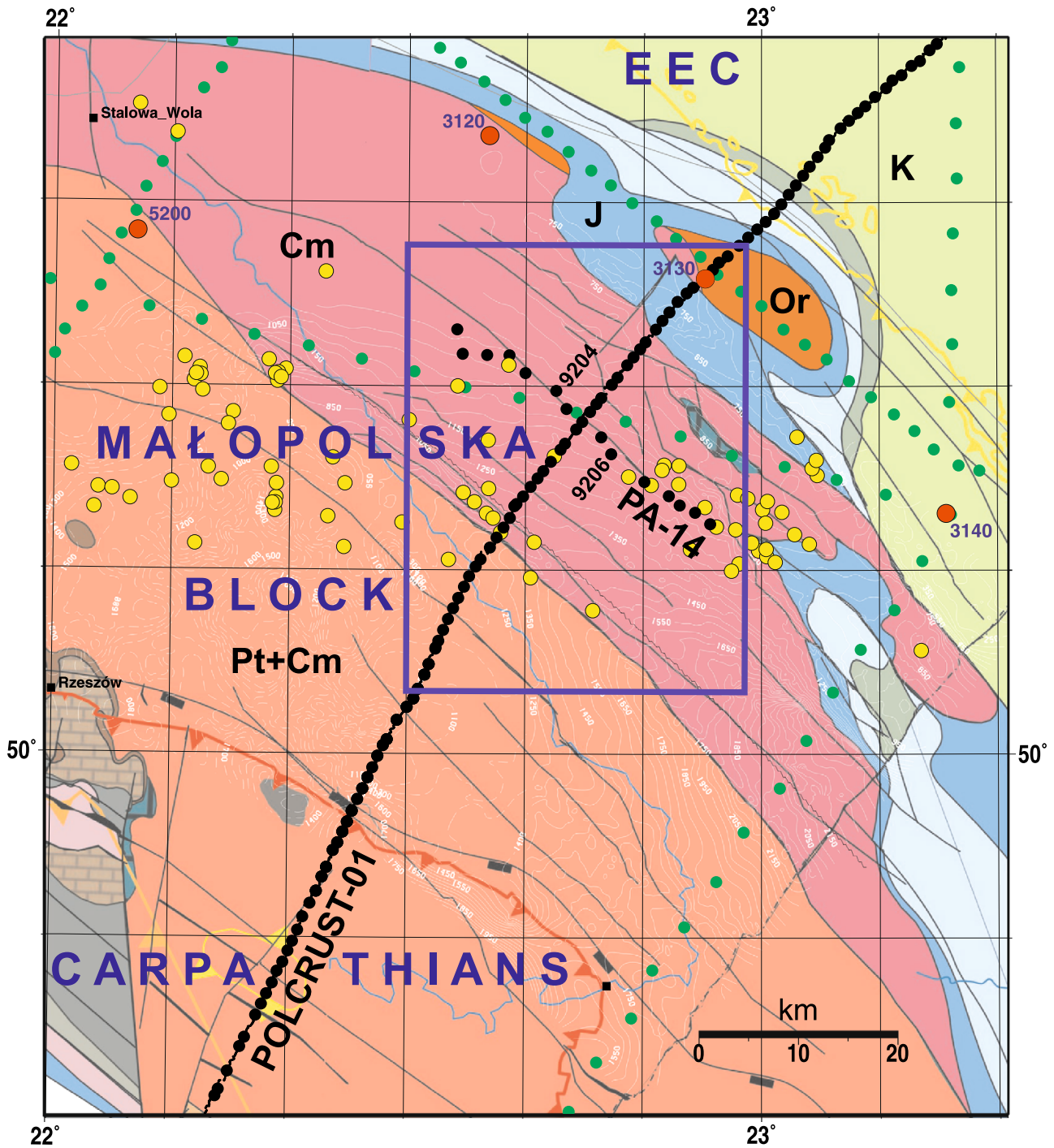

Figure 2

Geological map of the basement of the Carpathian Foredeep (MB) and location of the PA-14 experiment. Blue rectangle-extent of the model for PA-14 data inversion. Black points-POLCRUST-01 profile and receivers of PA-14 experiment, red and green points-CELEBRATION 2000 shot points and receivers, respectively, thin black lines-faults, yellow line-extent of the Carpathian Foredeep, red line-front of the Outer Carpathians, EEC-East European Craton. Pt Proterozoic, $\mathrm{Cm}$ Cambrian, Or Ordovician, $J$ Jurassic, $K$ Cretaceous

from $0.6 \mathrm{~km}$ in the North, at the Janów Fault (JF), to $2 \mathrm{~km}$ in the South, at the Catpathian deformation front (Fig. 1). Based on the earlier observations during acquisition in the northern part of the profile, in most of the shot gathers, maximum useful offset with good quality recordings was $15-20 \mathrm{~km}$. Based on this, the plausible penetration depth was conservatively estimated with a rule of thumb $(d \sim=x / 6)$ to be $\sim 2$ to $3 \mathrm{~km}$ - only slightly more than the thickness of the Miocene cover. Therefore, PA-14 experiment line was located in the area where Miocene thickness was minimal -0.5 to $1.5 \mathrm{~km}$, in order to probe as much of the sub-Miocene basement as possible. In this place, the refracted rays penetrate mostly top of the MB basement consisting of Cambrian rocks, partially covered by Mesozoic cover in 

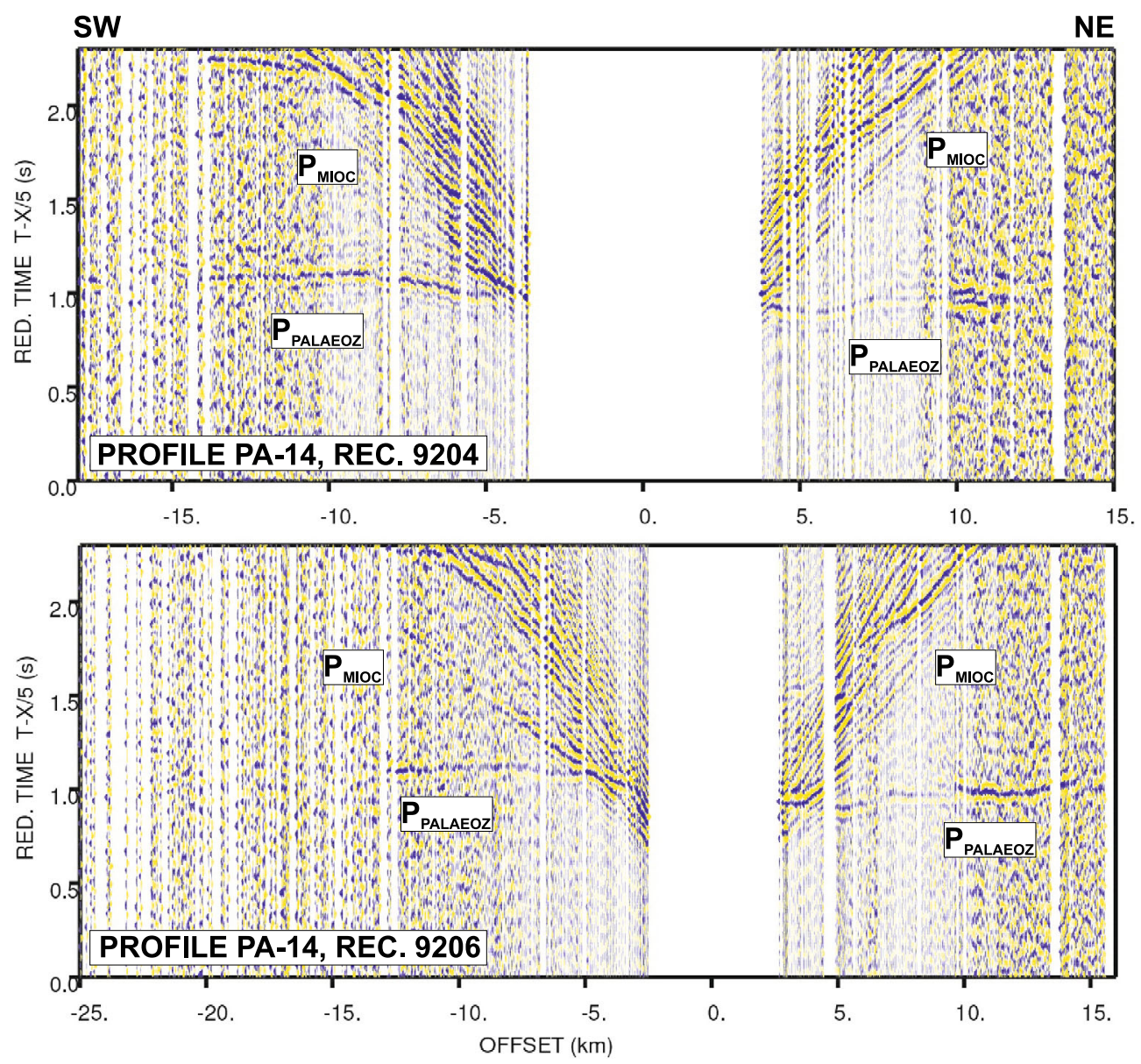

Figure 3

Examples of seismic sections (common receiver gathers) from PA-14 profile. Reduction velocity is $5 \mathrm{~km} / \mathrm{s}$. Traveltimes of the $\mathrm{P}_{\mathrm{PALAEOZ}}$ phase, representing the wave refracted in the Palaeozoic basement of the Carpathian Foredeep, were used as data for inversion. Locations of receivers 9204 and 9206 are shown in Fig. 2

the NE corner of the modelled area (blue rectangle in Fig. 2). Out of 14 deployed stations, 12 recorded useful data, with refractions from MB basement observed at $2-18 \mathrm{~km}$ offsets. Examples of the common receiver gathers are presented in Fig. 3. In total, the observations from the PA14 array resulted in $\sim 1800$ picks of refracted wave traveltimes. The traveltime data picking uncertainty, estimated based on the first arrivals" pulse width is $<5-20 \mathrm{~ms}$, depending on the signal to noise ratio.

To supplement the obtained model of anisotropy of the uppermost ( $<3 \mathrm{~km}$ depth) crust with information about deeper $(<12 \mathrm{~km}$ depth) crustal layers, a subset of data from CELEBRATION 2000 experiment were used. The experiment consisted of a net of
Figure 4

Examples of seismic sections from CELEBRATION 2000 experiment, profiles CEL-05 (SSW-NNE direction) and CEL-14 (WNW-ESE direction) for a shot point 5200 and b shot point 6210. Reduction velocity is $5.7 \mathrm{~km} / \mathrm{s}$. Note substantial differences in apparent velocity of the Pg phase depending on the orientation of the profiles. For locations of profiles and shot points, see Fig. 1

intersecting deep wide-angle profiles with in-line and fan recordings. Explosive sources located in $10-50 \mathrm{~km}$ intervals and recorders with $1.5-3 \mathrm{~km}$ spacing resulted in 3-D ray coverage and allowed modelling of the crustal and upper mantle structure down to $\sim 50$ to $60 \mathrm{~km}$ depth. Details of the data acquisition can be found in (Guterch et al. 2003). The experiment resulted in several 2-D and 3-D velocity 
(a)
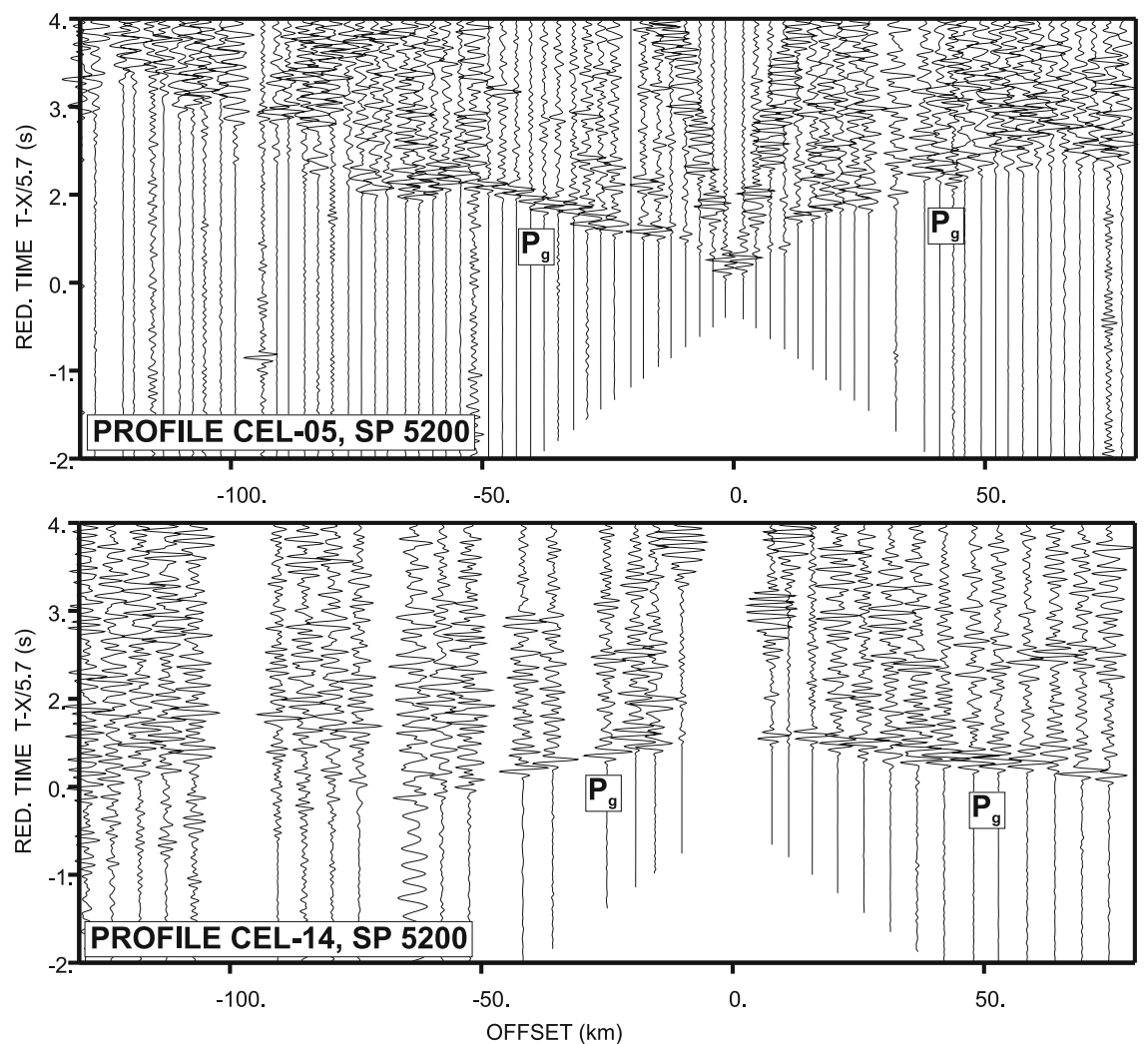

(b)
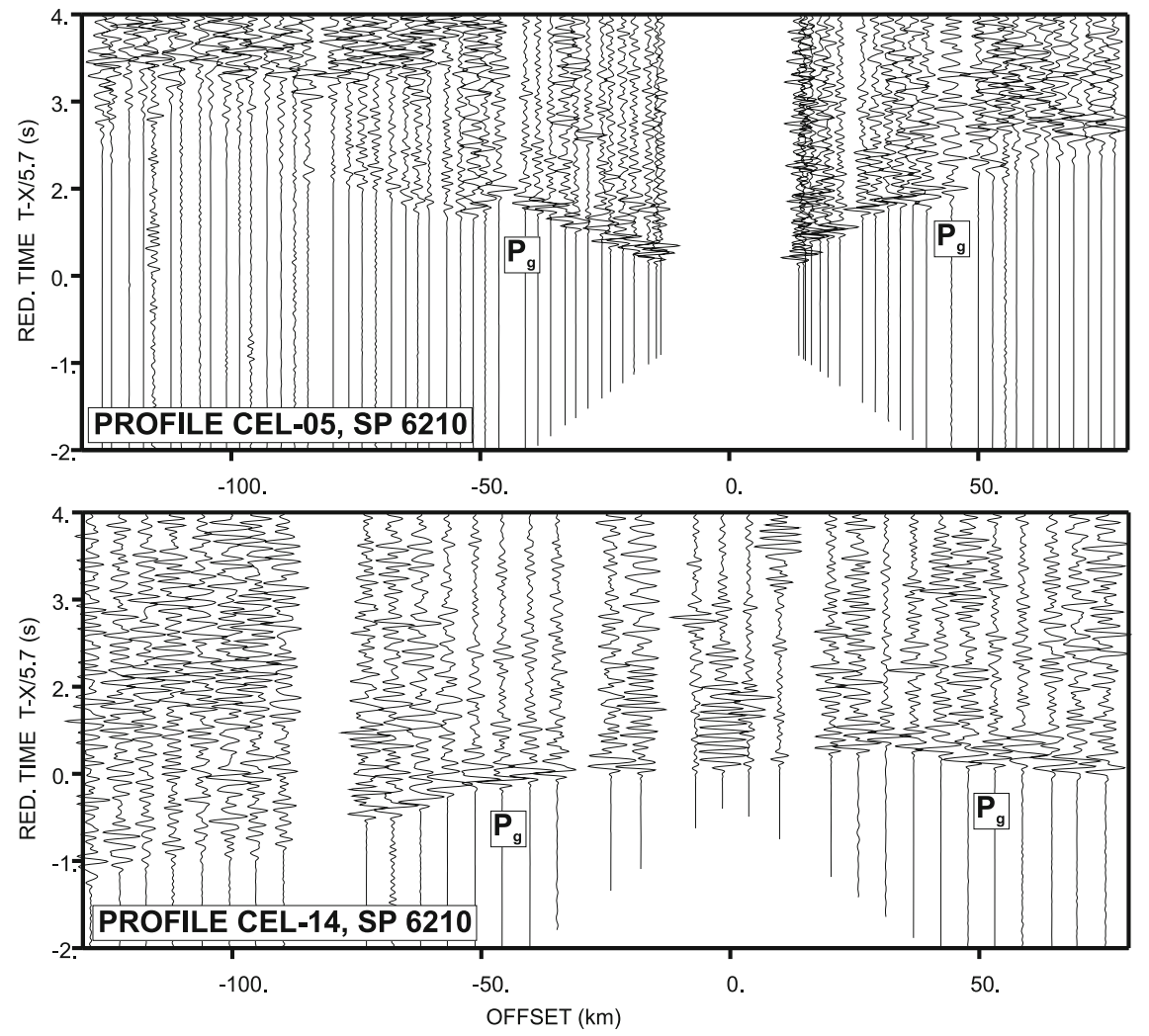


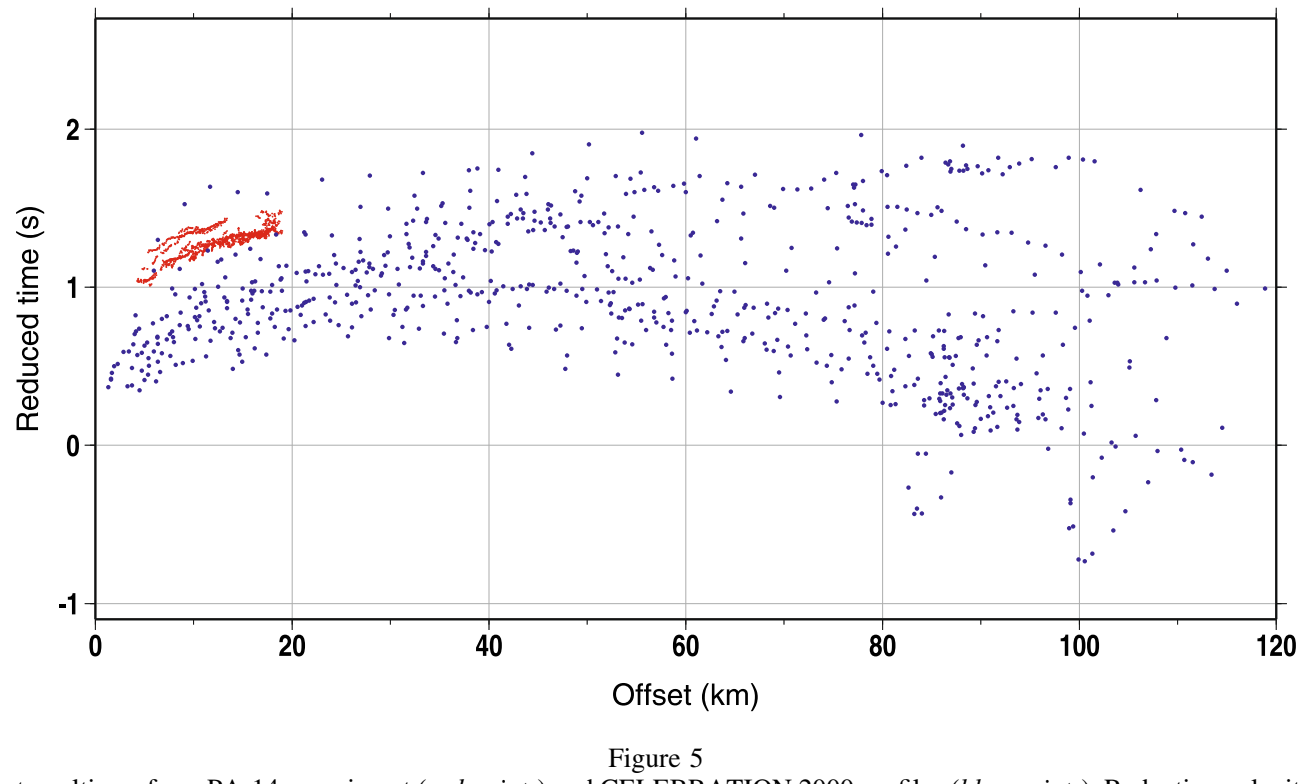

Observed Pg traveltimes from PA-14 experiment (red points) and CELEBRATION 2000 profiles (blue points). Reduction velocity is $5.7 \mathrm{~km} / \mathrm{s}$

models documenting the structure of the crust. Analysis of the off-line recordings from the experiment in SE Poland ( $\mathrm{MB}$ and $\mathrm{EB}$ area) revealed azimuthal variation of the velocity of the crustal refracted phase, explained by substantial $(8-10 \%)$ seismic anisotropy of the upper crust in a $300 \times 150 \mathrm{~km}$ large area, with fast velocity axis direction of $115^{\circ}$ (WNW-ESE). In this work, a subset of previously analysed data, limited to the $108 \times 100 \mathrm{~km}$ area surrounding the location of the PA14 experiment, was analysed. In total, from 740 traveltimes of the Pg phase recorded in this area, 645 traveltimes in 10-120 km offset range were used for inversion, assuring $\sim 12 \mathrm{~km}$ max. penetration depth. Examples of seismic record sections from two shot points are presented in Fig. 4. For each shot point, significant difference in the apparent velocity of the $\mathrm{Pg}$ phase can be observed for various directions (azimuths) of the wave propagation-from $\sim 5.2$ to $5.3 \mathrm{~km} / \mathrm{s}$ for the SSW-NNE oriented CEL-05 profile to $\sim 6.0$ to $6.2 \mathrm{~km} / \mathrm{s}$ for the WNW-ESE oriented CEL-14 profile. The traveltime picking uncertainty is estimated as $\sim 100 \mathrm{~ms}$.

The traveltimes of the Pg phase picked in the PA14 and CELEBRATION 2000 data are presented in Figs. 5 and 6. For both experiments, azimuthal diagrams show the dependence of the reduced travel times of $\mathrm{Pg}$ on the wave propagation direction, with smallest travel time (highest apparent velocity) in the WNW-ESE direction.

\section{Modelling Method: Anisotropic Delay-Time Inversion}

Several algorithms were developed for 3-D tomographic traveltime inversion in anisotropic media. However, the data coverage of both experiments was not dense and uniform enough to ensure resolving capability sufficient for detailed 3-D modelling of the $V p$ velocity and anisotropy distribution. Moreover, due to relatively small area of the PA-14 experiment, the studied MB basement was relatively uniform (in terms of structure and topography) and did not require the use of fine parametrization of the model and advanced tomographic algorithms. Therefore, modelling of the crustal anisotropy based on both data sets-PA-14 and CELEBRATION 2000 data-was performed by traveltime inversion using the delay-time method (Willmore and Bancroft 1960), modified to allow for weakly azimuthally anisotropic lower layer using Backus (1965) approximation, as described, e.g., by Song et al. (2001): 
(a)
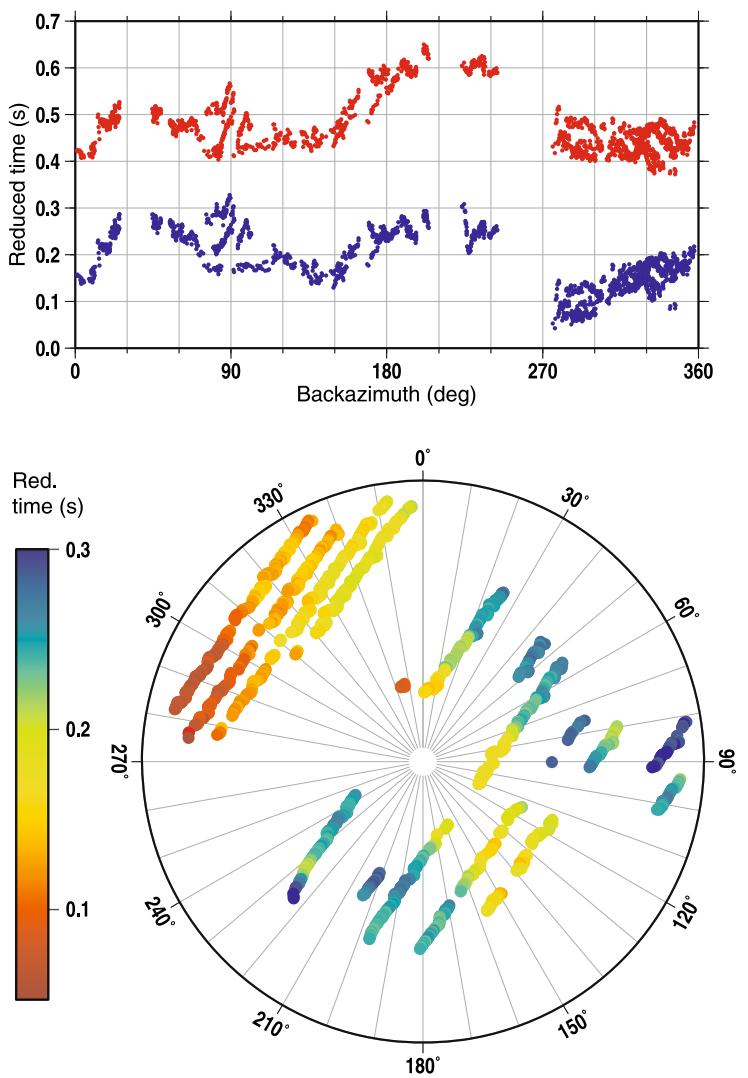

(b)
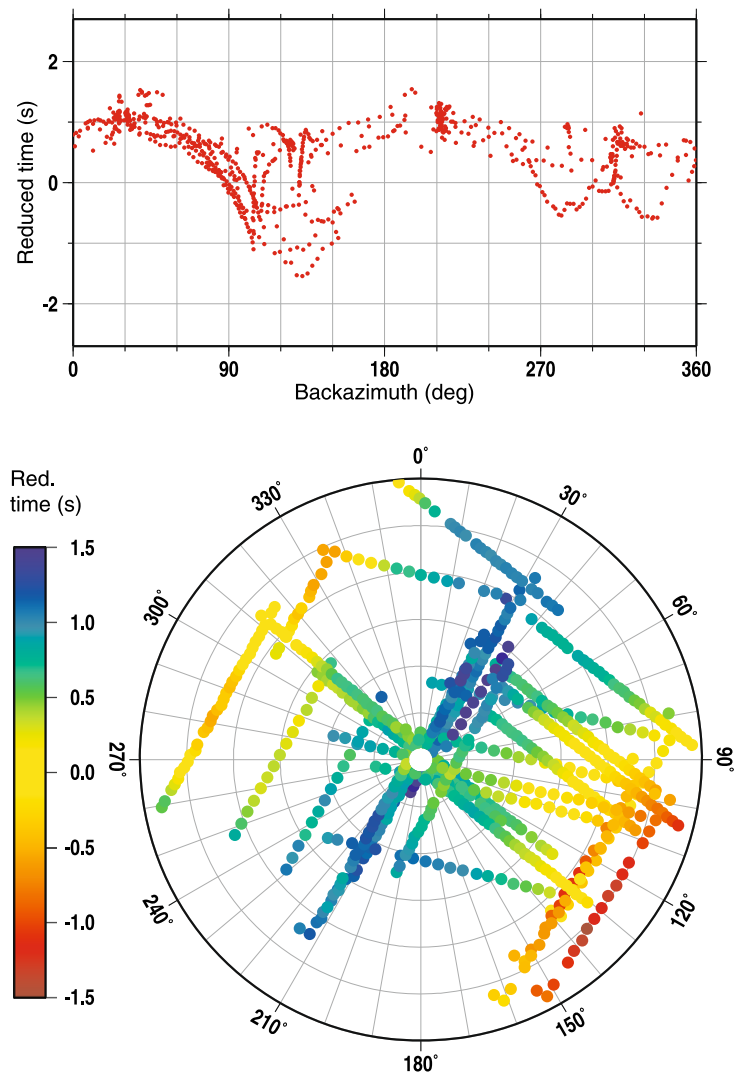

Figure 6

Azimuthal diagrams of Pg traveltime data. Polar coordinates $r, \varphi$ in bottom diagrams are the offset and ray backazimuth, respectively. a PA14 experiment: circle radius corresponds to $20 \mathrm{~km}$ offset. Reduction velocity is $5.0 \mathrm{~km} / \mathrm{s}$. Top: red points-uncorrected traveltimes, blue points - traveltimes corrected for the thickness of the Miocene CF sequences, based on TWT of near-vertical reflections (used for bottom diagram). b CELEBRATION 2000 data subset: circle radius corresponds to $120 \mathrm{~km}$ offset. Reduction velocity is $5.45 \mathrm{~km} / \mathrm{s}$

$\begin{aligned} t_{i j}= & a_{i}+b_{j}+D_{i j}\left(S_{0}+A \cos \left(2 \varphi_{i j}\right)+B \sin \left(2 \varphi_{i j}\right)\right. \\ & \left.+C \cos \left(4 \varphi_{i j}\right)+D \sin \left(4 \varphi_{i j}\right)\right),\end{aligned}$

where $D_{i j}$ is the distance from source $i$ to station $j, \varphi_{i j}$ is ray backazimuth, $S_{0}$ is (unknown) average slowness (1/ $V_{0}$ ) below the refracting interface and $a_{i}, b_{j}$ are unknown time delays for the $i$-th source and $j$-th receiver, respectively. $A, B, C$ and $D$ are unknown anisotropy parameters. The delays depend on the velocity and thickness of the upper layer. If $C$ and $D$ coefficients are small, as it is often the case, magnitude of the anisotropy can be expressed as $\mathrm{AN}=\left(A^{2}+B^{2}\right)^{1 / 2}$ and azimuth of fast velocity is defined as $\varphi_{\text {MAX }}=1 / 2 * \arctan (B / A)$. The set of Eq. (1) for all source-receiver pairs can be solved using, for example, the damped least squares (DLS) inversion for $a_{i}, b_{j}, S_{0}$ and anisotropy coefficients
$A, B, C$ and $D$. This method was used, e.g., by Hearn (1996) or Song et al. (2001) for mantle anisotropy studies. Růžek et al. (2003) and Kuo-Chen et al. (2013) also applied it for modelling of crustal anisotropy. Basic assumptions of the approach used here were described in more detail by Środa (2006). However, in this work, some further modifications of the method had to be applied, as described below.

In Eq. (1), $a_{i}$ and $b_{j}$ are independent variables. However, from the geometry of the measurements it follows that the delays for shots and receivers located close to each other should have similar value. Moreover, spatial variability of the delays should be constrained to obtain a realistically smooth solution. These constraints must be imposed on the solved inverse problem to obtain physically consistent 
model. One of possible approaches, applied in this work, is to parameterize the shot and receiver delay times $a_{i}$, and $b_{i}$ as values of a smooth function of $x$ and $\mathrm{y}$ coordinates, expressed as a linear combination of the first-degree polynomials and Fourier series of the $\mathrm{n}$-th order, both in 2 dimensions [as used, e.g., by Raitt et al. (1969)]:

$$
\begin{aligned}
\tau\left(x^{\prime}, y^{\prime}\right)= & p_{0}+p_{1} x^{\prime}+p_{2} y^{\prime}+p_{3} x^{\prime} y^{\prime} \\
& +\sum_{m=1}^{N} \sum_{n=1}^{N}\left(c_{m n} \sin \left(m \pi x^{\prime}\right) \sin \left(n \pi y^{\prime}\right)\right. \\
& +d_{m n} \sin \left(m \pi x^{\prime}\right) \cos \left(n \pi y^{\prime}\right)+e_{m n} \cos \left(m \pi x^{\prime}\right) \\
& \left.\sin \left(n \pi y^{\prime}\right)+f_{m n} \cos \left(m \pi x^{\prime}\right) \cos \left(n \pi y^{\prime}\right)\right),
\end{aligned}
$$

with $x, y$ coordinates rescaled by the model dimensions $L_{x}, L_{y}$ as $\left(x^{\prime}, y^{\prime}\right)_{\mathrm{i}}=(x, y)_{i} /\left(L_{x}, L_{y}\right)$. The order of the Fourier series controls the smoothness of the delay-times surface. In such parameterization, the model consists of: slowness $S_{0}$, anisotropy coefficients $A, B, C, D$ and the polynomial and Fourier series coefficients $p_{0} \ldots p_{3}, c_{m n}, d_{m n}, e_{m n}, f_{m n}$ (in total, 1 velocity parameter, 4 anisotropy parameters and $4+4 N^{2}$ delay times parameters).

Such parametrization works well for the acquisition geometry where seismic sources and receivers cover the same region, e.g., for CELEBRATION 2000 data set. In such case, the $a_{i}$ and $b_{j}$ terms are related due to the constraints applied. However, in the case of PA-14 experiment, sources and receivers were located in separate areas (along separate, perpendicular lines). Such geometry results in excessive freedom in the inverse problem, and leads to solutions where azimuthal traveltime variations are compensated largely by (unrealistic) variations of the $a_{i}$ and $b_{j}$ delays surface, rather than by the anisotropy parameters. To avoid such an effect, the PA-14 shot and receiver delays were calculated based on available data on the depth of the CF and introduced to the inversion as fixed values, thus reducing the number of unknowns to $\mathrm{S}_{0}, \mathrm{~A}$ and $\mathrm{B}$. Precise information about shot delays were obtained from the values of TWT to the horizon marking the CF basement in the stacked time section of the POLCRUST-01 line. The receiver delays were obtained from a map of the TWT to CF basement (Krzywiec et al. 2008) based on dense net of the industrial seismic reflection profiles.

The delay-time method relies on straight-line, near-horizontal refracted ray path approximation, valid for a negligible vertical velocity gradient. However, previous 2-D modelling of POLCRUST-01 and CELEBRATION 2000 data revealed substantial vertical $V p$ gradient in the upper crust. Therefore, in this work, a modified equation for traveltime in the gradient medium (Enderle et al. 1996) was used, similarly as described by Środa (2006). Using a gradient formula makes the inversion problem nonlinear and requires an iterative linearized procedure, described in detail by Środa (2006). For the data modelled in this study, 2 iterations were sufficient. The vertical velocity gradient values used for PA-14 and CELEBRATION 2000 data were 0.010 and $0.035 \mathrm{~s}^{-1}$, respectively. The value of the damping coefficient $\lambda$ was set to 0.002 .

In order to confirm that anisotropy is necessary to explain the distribution of traveltimes and to evaluate the significance of adding anisotropic parameters to the model, inversion was performed for three cases: for isotropic velocity model, for anisotropic model with $2 \varphi$ dependence only and for anisotropic model with $2 \varphi$ and $4 \varphi$ terms. The latter resulted in a slightly better fit than the case limited to $2 \varphi$ term, but the results did not differ significantly. Errors of the model parameters, presented in Table 1, were estimated

Table 1

Results of the PA-14 data inversion and of the significance test

\begin{tabular}{lllllllllll}
\hline Method & $V p(\mathrm{~km} / \mathrm{s})$ & $\mathrm{AN}(\%)$ & $\varphi_{\max }\left({ }^{\circ}\right)$ & $N_{\text {data }}$ & $N_{\text {par }}$ & DF & RMS dT (s) & $F_{\text {calculated }}$ & $F_{\text {table }}$ & Improvement \\
\hline ISO (I) & $5.2 \pm 0.02$ & - & - & 1822 & 446 & 1376 & 0.054 & - & & \\
ANI 2 $\varphi$ (A2) & $5.0 \pm 0.02$ & $5.8 \pm 0.1$ & $130 \pm 0.7$ & 1822 & 448 & 1374 & 0.037 & A2/I: 315 & 4.61 & YES \\
ANI 2 $\varphi, 4 \varphi(\mathrm{A} 4)$ & $5.0 \pm 0.02$ & $5.7 \pm 0.1$ & $133 \pm 0.7$ & 1822 & 450 & 1372 & 0.035 & A4/I: 186 & 3.32 & YES \\
& & & & & & & & A4/A2: 39 & 4.61 & WEAK \\
\hline
\end{tabular}

$N_{\text {data }}$ number of data points, $N_{\text {par }}$ number of parameters, $D F$ number of degrees of freedom $\left(N_{\text {data }}-N_{\text {par }}\right)$ 
using the bootstrap method (Efron 1979). However, this is an estimate of random data errors only. The errors resulting from assuming a simple model to image an inhomogeneous structure, hard to estimate reliably, were not taken into account and, therefore, the actual uncertainty is likely to be larger.

The Backus (1965) formula applies for near-horizontal rays in a weakly anisotropic medium and is not constrained to any particular symmetry. However, in the case of measurements confined to a horizontal plane and near-horizontal rays, the only parameters that can be resolved are mean velocity, anisotropy $(\mathrm{AN})$ and azimuth of fast velocity $\varphi_{\text {MAX }}$. With such a simple set of model parameters, only the simplest symmetry of the medium should be assumed-a transversally isotropic symmetry with horizontal symmetry axis (HTI). Such an assumption is realistic, as layered/foliated or fractured rocks often exhibit transverse isotropy. In such a medium, the fast velocity plane is parallel to the foliation/layering surfaces, with slowest velocity (symmetry axis) in perpendicular direction. In general, depending on degree of folding (or on the dip of fractures), the direction of symmetry axis can vary from vertical (VTI) (undeformed, horizontally layered rock) through tilted (TTI) (consistently inclined folds or dipping fractures) to horizontal symmetry axis (HTI) (consistently oriented, near-vertical folds or fractures). Vertical orientation symmetry axis causes no azimuthal anisotropy—subhorizontal rays all propagate with the same velocity, along (or at similar angle to) the fast plane, independently of their azimuth. Occurrence of azimuthal anisotropy implies tilted to vertical orientation of symmetry axis. In case of measurements limited to horizontal plane (this study), the magnitude of observed azimuthal anisotropy (AN) depends on two factors-elastic properties of the rock complex (intrinsic rock anisotropy, AI) and symmetry axis dip-which cannot be uniquely determined based on single parameter. Therefore, assumption of HTI model (arbitrary setting of the axis dip to $90^{\circ}$ ), instead of a more general TTI model, is a simplification aiming to remove this nonuniqueness, even if TTI model could be, geologically, more plausible. Another approximation results from simple model parametrization-representation of a large fragment of the crust by constant parameters and assuming that possible inhomogeneities can be neglected. In the next chapter, besides the AN values resulting from inversion based on the theoretical, idealized HTI model, also an estimate of the AI (intrinsic rock anisotropy) will be presented, using more realistic TTI model which takes into account geological data about the measured stratal dips of Palaeozoic/Ediacaran sequences in the study area.

\section{Results}

Results of the anisotropic traveltime inversion of fan recordings of the refractions from the $\mathrm{MB}$ are shown in Table 1. The MB Cambrian (and deeper Ediacaran?) basement is characterized by $\sim 6 \%$ HTI anisotropy (AN), with $130^{\circ}$ azimuth of the fast velocity axis axis and mean $V p$ of $5.0 \mathrm{~km} / \mathrm{s}$ (Fig. 7). The depth of ray penetration beneath the top of the Cambrian/Ediacaran basement for the PA-14 was conservatively estimated as $\sim 0.5 \mathrm{~km}$. Therefore, based on the PA-14 data, anisotropy was determined down to $\sim 500 \mathrm{~m}$ below the top of the basement, located at about $0.5 \mathrm{~km}$ in the North to about $1.5 \mathrm{~km}$ in the South. The RMS residual for the final anisotropic model is $0.037 \mathrm{~s}$, while for the isotropic model the residual is much higher- $0.054 \mathrm{~s}$. Therefore, anisotropic (HTI) solution provides better fit to the observed data. The final anisotropic RMS residual is still higher than the estimated observed data uncertainty $(<0.010 \mathrm{~s})$, most likely because simple parameterization of the model does not allow to fit possible inhomogeneities of the MB basement. This may be also the reason of two extrema (at $\sim 90^{\circ}$ and $\sim 270^{\circ}$ ) in the (otherwise uniform) azimuthal distribution of RMS residuals. However, azimuthal distribution of the residuals is free of the $180^{\circ}$ periodicity, which was clearly visible in the traveltime data, what proves that even such a simple model parametrization gives a reliable and meaningful result, even if it leaves some crustal features unexplained. The ray density for PA-14 data is presented in Fig. 8.

Model parameters from anisotropic (HTI) inversion of subset of CELEBRATION 2000 traveltimes are summarized in Table 2. They characterize Małopolska Block Cambrian and Ediacaran rocks in a 

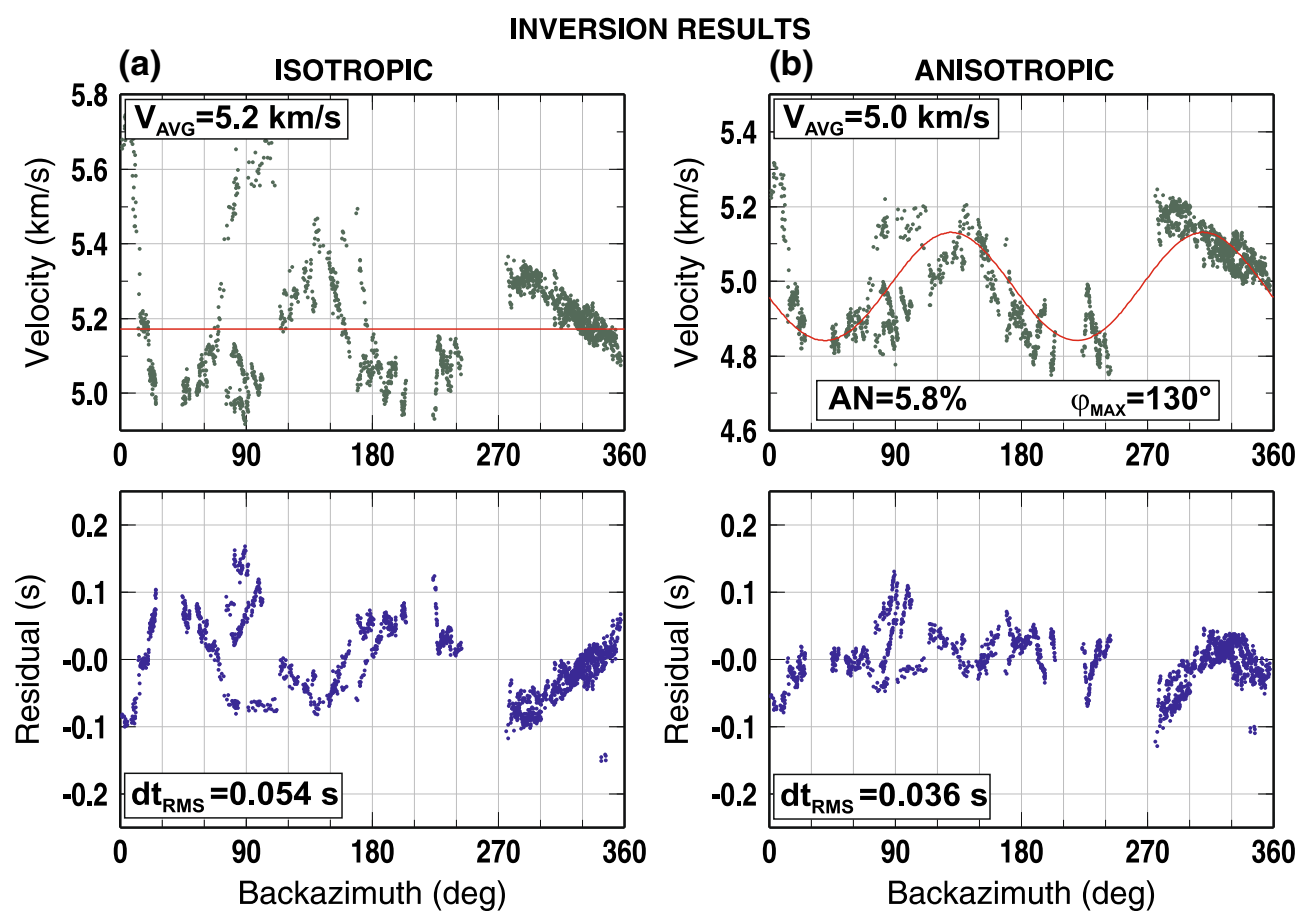

Figure 7

Results of the isotropic (a) and anisotropic delay-time inversion (b) of the PA-14 data set. Red line-modelled velocity, green pointsobserved velocity, blue points - traveltime residuals

$120 \times 100 \mathrm{~km}$ area down to $\sim 12 \mathrm{~km}$ depth. The results document $9.6 \%$ HTI anisotropy (AN) with $126^{\circ}$ orientation of the fast velocity axis (Figs. 9, 10). The mean $V p$ is $5.7 \mathrm{~km} / \mathrm{s}$ (compared to $5.9 \mathrm{~km} / \mathrm{s}$ for the isotropic model). For assumed vertical $V p$ gradient of $0.035 \mathrm{~s}^{-1}$, the average $V p$ at the bottom of studied depth interval $(\sim 12 \mathrm{~km})$ is $\sim 6.1 \mathrm{~km} / \mathrm{s}$. The time delays are in range $0.35-0.80 \mathrm{~s}$. The delay values (Fig. 10) depend on the low-velocity (Miocene to Mesozoic) cover thickness and velocity. Obtained range of delays corresponds roughly to the $0.7-4 \mathrm{~km}$ thickness of the low-velocity cover (assuming velocities in $2-4 \mathrm{~km} / \mathrm{s}$ range). The HTI model results in RMS residual of $0.13 \mathrm{~s}$, which proves a better fit than in case of the isotropic velocity model-0.33 s. The RMS for the HTI model is similar as estimated data uncertainty $(\sim 0.1 \mathrm{~s})$ and the distribution of residuals does not show any pronounced dependence on the azimuth of the ray. It means that the inversion successfully mapped inhomogeneous sedimentary cover of the MB and $Ł B$ (Mesozoic/Cainozoic Carpathian flysch in SW, Mesozoic cover of the $\mathrm{EB}$ in the NE, Miocene Carpathian Foredeep with thickness varying from 0 to $2 \mathrm{~km}$ ) into shot and receiver delays. Obtained values for $V p$, anisotropy and time delays in both experiments are meaningful only in the regions of the models with sufficiently high ray density (shown in Figs. 8, 10).

Measured values of azimuthal anisotropy (AN of 6 and $9.5 \%$ ) could correspond to similar magnitudes of intrinsic anisotropy of foliated rocks (AI) if vertical orientation of foliation planes (HTI symmetry) is assumed (in such a case, minimal angle between the symmetry axis and ray direction is close to $0^{\circ}$ ). However, data from numerous wells reaching the Cambrian/Ediacaran basement of the $\mathrm{CF}$ indicate steep but non-vertical stratal dips (TTI symmetry). The stratal dips are largely $\sim 40^{\circ}$ to $80^{\circ}$, what corresponds to minimum angle between ray direction and symmetry axis in range of $\sim 10^{\circ}$ to $50^{\circ}$. In this case, magnitude of intrinsic rock anisotropy (AI) can be expected to be even bigger than reported values of azimuthal anisotropy AN. Based on the formula for slowness of a ray inclined with respect to symmetry 


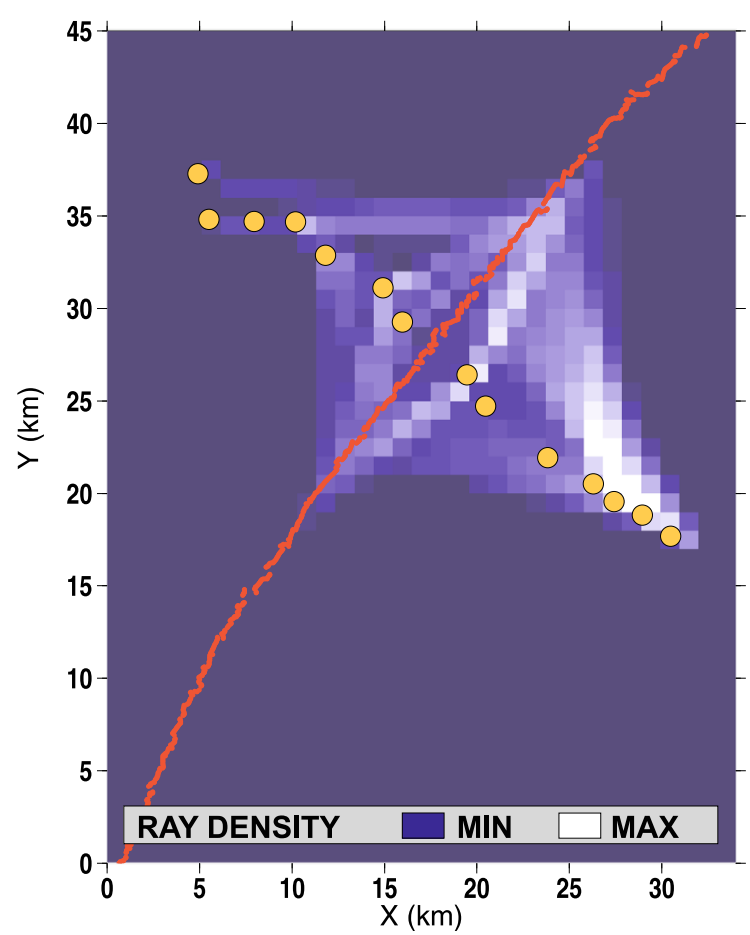

Figure 8

Ray density corresponding to the traveltime data from PA-14 experiment. Red points-POLCRUST-01 line, yellow pointsreceiver locations along the $\mathrm{PA}-14$ line

axis in a TI medium (Eberhart-Phillips and Mark Henderson 2004), the relationship between the horizontally observed azimuthal anisotropy, intrinsic rock anisotropy (elastic property characterizing the rock itself) and the inclination of the symmetry axis can be written as:

$$
\mathrm{AI}=\mathrm{AN} \cos ^{-2}(\vartheta)=\mathrm{AN} \sin ^{-2}(a),
$$

where AI is the magnitude of intrinsic anisotropy characterizing the rock or rock complex, $\mathrm{AN}$ is the magnitude of horizontally measured azimuthal $V p$ anisotropy, $\vartheta$ is the minimal angle between ray direction and symmetry axis (=slow velocity direction). In the case when sub-horizontal direction of rays can be assumed, the latter angle $\vartheta$ is equivalent to inclination of the symmetry axis with respect to horizontal, or, alternatively, $\alpha=\left(90^{\circ}-\vartheta\right)$ corresponds to inclination of the fast plane of foliation/ layering (stratal dip in case of layered/foliated rocks). In order to evaluate typical dip of strata in the study area, lithology data from several wells available in the digital archive of the Polish Geological Institute (Central Geological Database 2016) were analysed. In the region within $50^{\circ} 10^{\prime}-50^{\circ} 30^{\prime} \mathrm{N}$ latitude and $22^{\circ}-23^{\circ} 30^{\prime} \mathrm{E}$ longitude range, extending over part of the study area, descriptions of 86 well cores penetrating to Cambrian or Ediacaran basement contained information about the layer dips. Resulting histograms of stratal dips of Miocene (and Mesozoic), Cambrian and Ediacaran sequences are presented in Fig. 11. The dips of Miocene layers, lying mostly sub-horizontally, are largely in $0-15^{\circ}$ range, as visible also in POLCRUST-01 section (Malinowski et al. 2013) and in other seismic reflection data from this area. Therefore, even assuming that the Miocene cover could be somewhat anisotropic, it would be anisotropy of VTI symmetry, not detectable by described experiment, and it should not bias or distort the measurements of azimuthal anisotropy of the deeper layers. Cambrian sequences dip is mostly in $10-90^{\circ}$ range, while for Ediacaran rocks-mostly in $40-90^{\circ}$ range. Weighted averages for these three stratigraphic groups are, respectively, $7^{\circ}, 49^{\circ}$ and $58^{\circ}$. Based on these values, scaling factors $\sin ^{-2}(\alpha)$ for estimating rock anisotropy AI for Cambrian and Ediacaran sequences are 1.76 and 1.4, respectively. Therefore, for Cambrian sequences sampled by PA-

Table 2

Results of the CELEBRATION 2000 data inversion and of the significance test

\begin{tabular}{lllllllllll}
\hline Method & $V p(\mathrm{~km} / \mathrm{s})$ & AN $(\%)$ & $\varphi_{\max }\left({ }^{\circ}\right)$ & $N_{\text {data }}$ & $N_{\text {par }}$ & DF & RMS dT (s) & $F_{\text {calculated }}$ & $F_{\text {table }}$ & Improvement \\
\hline ISO (I) & $5.9 \pm 0.04$ & - & - & 645 & 367 & 278 & 0.33 & - & & \\
ANI 2 $\varphi$ (A2) & $5.7 \pm 0.03$ & $9.6 \pm 0.4$ & $126 \pm 1.3$ & 645 & 369 & 276 & 0.13 & A2/I: 231 & 4.61 & YES \\
ANI 2 $\varphi, 4 \varphi$ (A4) & $5.7 \pm 0.03$ & $9.6 \pm 0.3$ & $125 \pm 1.2$ & 645 & 371 & 274 & 0.12 & A4/I: 120 & 3.32 & YES \\
& & & & & & & & A4/A2:11 & 4.61 & WEAK \\
\hline
\end{tabular}

$N_{\text {data }}$ number of data points, $N_{\text {par }}$ number of parameters, $D F$ number of degrees of freedom $\left(N_{\text {data }}-N_{\text {par }}\right)$ 

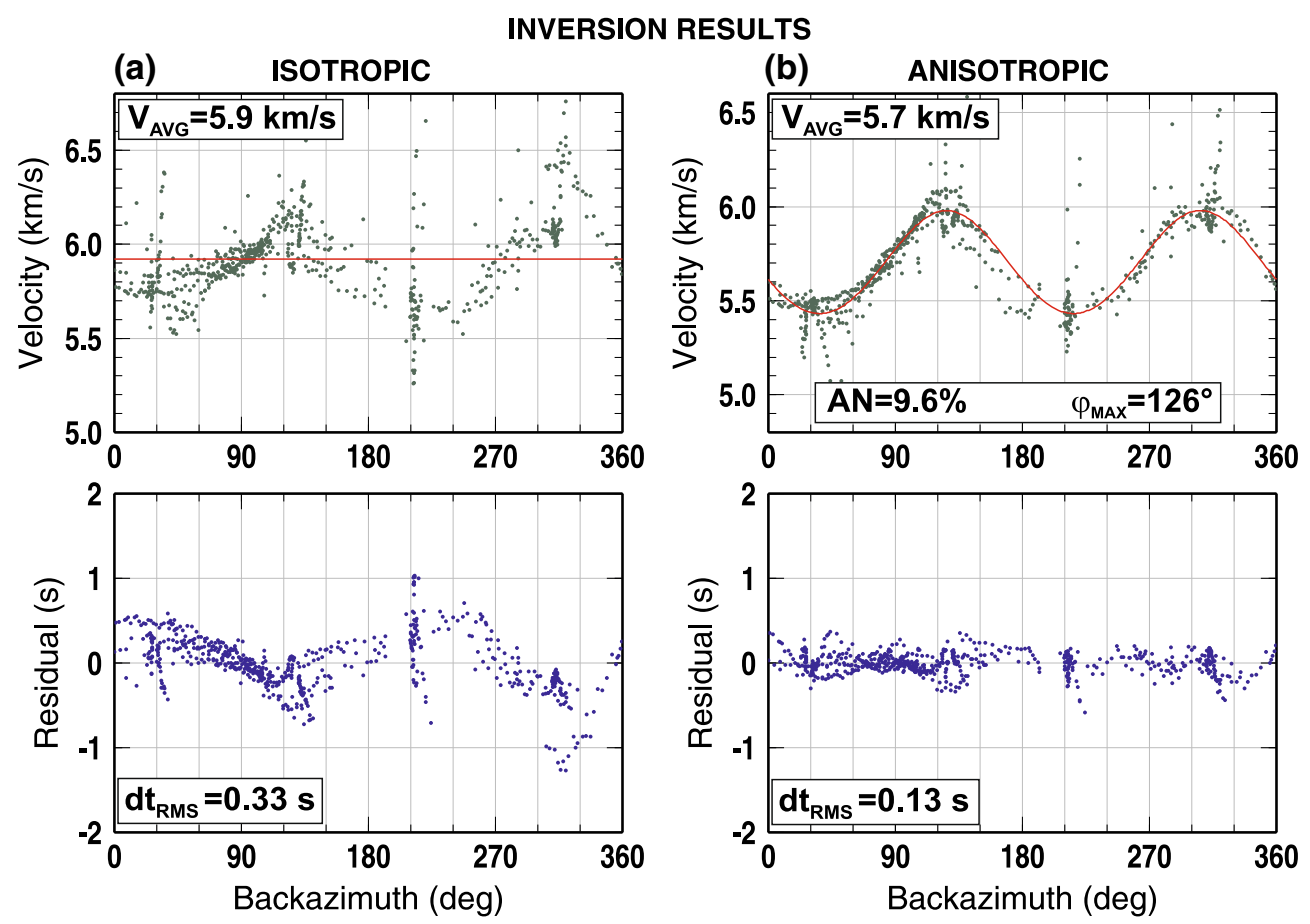

Figure 9

Results of the isotropic (a) and anisotropic delay-time inversion (b) of the CELEBRATION 2000 data set. Red line-modelled velocity, green points-observed velocity, blue points—traveltime residuals

(a)

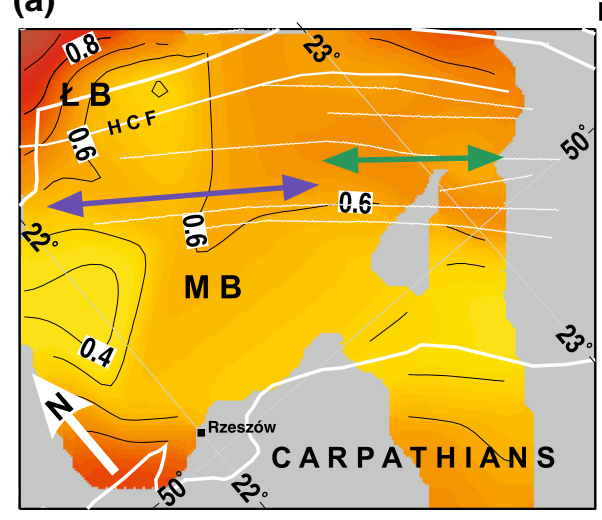

(b)

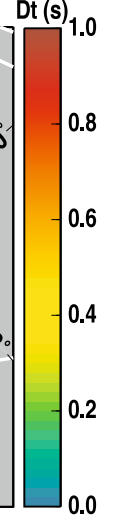

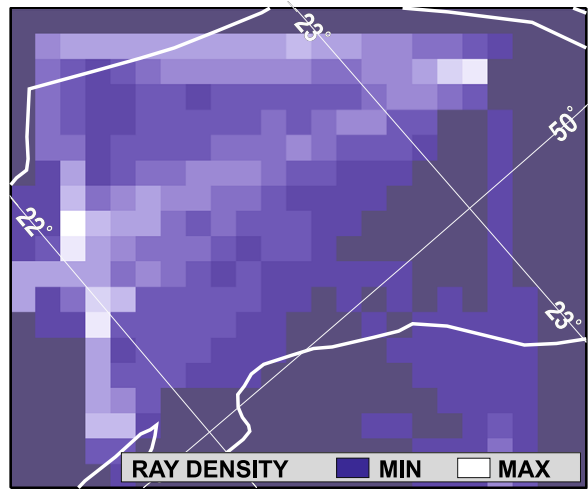

Figure 10

a distribution of time delays for anisotropic inversion (isolines every $0.1 \mathrm{~s}$ ) Blue arrow-direction of fast velocity axis from inversion of CELEBRATION 200 data, green arrow-direction of fast axis from inversion of PE-14 data. The arrows are located approximately in the regions of best ray coverage for both experiments. The lengths of the arrows are proportional to obtained anisotropy values. White linestectonic boundaries and faults, grey area - parts of the model unresolved due to zero or low data coverage. b map of ray density. $\measuredangle B$ Łysogóry Block, $M B$ Małopolska Block, HCF Holy Cross Fault

14 measurements with $\mathrm{AN}=\sim 6 \%$, the intrinsic rock anisotropy (AI) can be tentatively estimated as reaching $\sim 10 \%$. Similarly, for Ediacaran sequences sampled by deeper-reaching CELEBRATION 2000 data with $\mathrm{AN}=\sim 9.5 \%$, the estimated rock anisotropy (AI) may reach $\sim 13 \%$. These crude estimates 

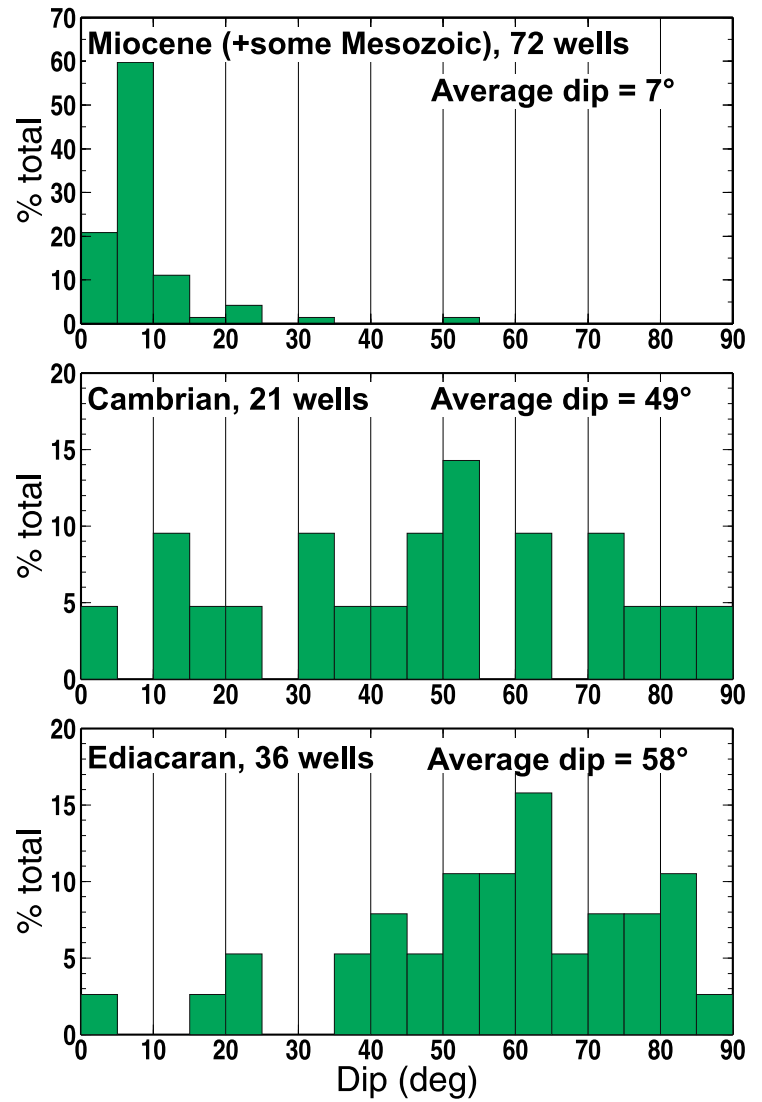

Figure 11

Histograms of stratal dip of Miocene, Cambrian and Ediacaran sequences measured in 86 wells reaching basement of Carpathian Foredeep (for well locations, see Fig. 2)

are based on several assumptions and simplifications, e.g., that the anisotropy is caused largely by dipping (folded) layered/foliated rocks (or dipping oriented cracks and fractures) and that the orientation of folds/ cracks is consistent in most of the area. Therefore, these values cannot be considered as a precise evaluation, it is rather an indication that the actual magnitude of anisotropy of studied rock complexes may be higher (by a factor of $\sim 1.5$ ) than the azimuthal $V p$ anisotropy value observed from measurements in one plane with near-horizontal orientation of seismic rays.

The closer look on the distribution of stratal dips in Fig. 11 shows that for Ediacaran sequences the dips are concentrated at high $\left(50-85^{\circ}\right)$ angles, while for neighbouring/overlying Cambrian layers the most of dip values are distributed more uniformly in the broader range $\left(10-75^{\circ}\right)$, including also small or moderate angles. This points out to heavier deformations of the Ediacaran rocks, affected subsequently by Cadomian and, most likely, Early Caledonian orogeny, compared to less deformed Cambrian strata, affected only by the later, Early Caledonian event. This is consistent with observed differences in anisotropy magnitude in Ediacaran versus Cambrian strata; however, these differences may be as well related to different depth ranges sampled by both experiments.

Younger Palaeozoic (including Ordovician) and Mesozoic sequences, overlying Ediacaran/Cambrian layers, are found largely along the SW border of the study area. From available studies (e.g., Buła and Habryn 2011; Karnkowski and Głowacki 1961) it follows that they are often tectonically altered, with varying intensity, by Caledonian and later deformational episodes. However, in general, observed stratal dips are significantly lower (from zero to few tens of degrees) than for the Ediacaran/Cambrian sequences, except in localized zones of strong tectonic deformations. This suggests that observed seismic azimuthal anisotropy, characterizing the SE part of Małopolska Block, is most likely caused predominantly by Cadomian and Early Caledonian compressional or transpressional deformations of intrinsically anisotropic basement rocks, with minor contribution of later deformational events affecting this area. It should be noted that the deformations are not understood here as the source of the intrinsic anisotropy of the rock. The intrinsic anisotropy of the low-grade mestasediments (as, e.g., the rocks building the MB basement) is thought to be a result of preferred (sub-horizontal) orientation of flat-shaped (and strongly anisotropic) mineral crystals during the time of deposition or of fine (sub-horizontal) layering of the sedimentary sequences. Further metamorphism, due to increasing pressure of the overlying sequences and to temperature, is likely to enhance the preferred orientation of rock constituents and to increase the intrinsic anisotropy. The compressional deformations, which obviously led to geologically observable tight folding of the MB basement sequences, are invoked here as the reason of steep, sub-vertical dip of foliation/layering, and, in consequence, of reorientation of the symmetry of the 
medium from VTI (at the time of deposition) to HTI/ TTI (after deformation), producing azimuthal variation of seismic velocities (azimuthal anisotropy). The azimuthal anisotropy detected in described experiment would not be observed for flat-lying anisotropic rocks with VTI symmetry (assuming the absence of coherently oriented cracks).

\section{Discussion and conclusions}

The azimuthal dependence of seismic P-wave velocity was observed in the PA-14 data. It is explained by a transversally isotropic model of the upper crust with (sub?)horizontal symmetry axis and fast velocity plane oriented (sub?)vertically, in WNW-ESE direction. Based on PA-14 data, anisotropy was found in the Cambrian low-grade metasediments of the $\mathrm{MB}$, forming the basement of the Carpathian Foredeep. The top of the anisotropic Cambrian basement is located at $0.5-1.5 \mathrm{~km}$ depth. Observed anisotropy parameters are consistent with larger-scale anisotropy detected using CELEBRATION 2000 data from a broader area and larger depth interval (down to $\sim 12 \mathrm{~km}$ ) in Cambrian and Ediacaran rocks. The measured azimuth of fast velocity axis is $130^{\circ}$ (uppermost crust, PA-14 data) to $126^{\circ}$ (upper crust, CELEBRATION 2000 data). These values agree well with orientation of faults in this area.

The maximal observed magnitude of the anisotropy $(9.5 \%)$ is unusually large, considering that it is an average from a large $(120 \times 100 \mathrm{~km})$ area, which means that locally the anisotropy may be higher. However, laboratory measurements of the metasedimentary rocks samples give even higher values$12 \%$ for phyllites, $16 \%$ for mica schists, $21 \%$ for slates and 5-10\% for gneisses (Christensen and Mooney 1995). Godfrey et al. (2000) reported 9\% anisotropy in Cretaceous Chugach phyllite samples, 13\% anisotropy for samples of Mesozoic Haast schists and 20\% anisotropy for Early Ordovician Poultney slates. Johnston and Christensen (1995) measured 20-30\% Vp anisotropy in Devonian shale samples. Unfortunately, no results of laboratory measurements of anisotropy of MB basement rocks from the study area are available.
Seismic anisotropy observed in the MB can be explained by preferred orientation of anisotropic minerals (e.g., mica) in foliated rocks-shales ( $V p$ of $3-4.5 \mathrm{~km} / \mathrm{s}$ ), phyllites ( $V p$ of $6.0-6.3 \mathrm{~km} / \mathrm{s}$ ), mica schists ( $V p$ of $5.8-6.4 \mathrm{~km} / \mathrm{s})$, gneisses $(5.5-6.2 \mathrm{~km} / \mathrm{s}$ ) or slates $(6.0-6.2 \mathrm{~km} / \mathrm{s})$. Observation of azimuthal anisotropy suggests that the rock foliation planes are oriented subvertically or at a high angle (HTI/TTI symmetry), due to tight folding of rocks, with consistent orientation of fold axes over a large area. Data about the deformations and stratal dips in the MB area suggest that this is a plausible scenario. The dips measured in boreholes penetrating the Ediacaran of the $\mathrm{MB}$ are mostly in the $50-85^{\circ}$ range, reaching up to $90^{\circ}$. To the NW of the study area, in the Holy Cross Mountains representing the outcrop of Palaeozoic rocks still belonging partly to the studied Małopolska Block, reported stratal dips are in the range of $30-90^{\circ}$ (Mizerski 1992) or 60-70 (Stupnicka 1986). Another factor contributing to the anisotropy, especially in the uppermost crust, may also be the WNW-ESE oriented cracks, as the faults observed in this area have similar orientation.

Observed azimuthal seismic anisotropy is thus interpreted as a result of heavy compressional/transpressional tectonic deformations of intrinsically anisotropic Cambrian to Ediacaran low-grade metasediments of the $\mathrm{MB}$ basement during the Cadomian orogenic event in Late Ediacaran and during Early Caledonian deformation and accretion of terranes to the EEC margin. The geological imprints of these events evidence a SSW-NNE compression direction and WNW-ESE course of the resulting deformational structures, consistent with the observed fast velocity azimuth.

Presented work shows that low-cost, wide-angle off-line recordings of seismic sources from a nearvertical reflection profile supplied additional data on the structure of the sedimentary sequences. Analysis of these data provides more detailed information about seismic velocity and its azimuthal variations, not available from standard near-vertical profiling, and contributes to more complete image of the uppermost crust. Moreover, a small-scale $(<20 \times 20 \mathrm{~km}$ area) PA-14 experiment is a valuable confirmation of previously reported anisotropy based on large-scale $(\sim 300 \times 150 \mathrm{~km}$ area $)$ experiment 
(Środa 2006). Observation of anisotropy of similar amplitude and fast axis orientation, over much smaller, and, thus, possibly more homogeneous crustal fragment, is an independent proof for $\mathrm{MB}$ anisotropy.

Summarizing, the analysis of azimuthal trend observed in traveltimes of crustal refractions from two wide-angle experiments-PA-14 and CELEBRATION 2000—evidenced substantial anisotropy of the Paleozoic to Ediacaran basement of the SE Małopolska Block. A model of transversally isotropic medium with a horizontal symmetry axis (HTI) and fast plane oriented in WNW-ESE direction was sufficient to fit the traveltime data; however, more realistic TTI mode was also discussed. Petrologically, the anisotropy of upper crustal rocks is attributed to foliation fabrics and associated preferred mineral orientation in intrinsically anisotropic low to medium grade metamorphic rocks. Seismically observed azimuthal anisotropy is an effect of tight folding of these anisotropic sequences and resulting sub-vertical orientation of foliation fabrics due to the compressional and/or transpressional deformations and crustal shortening. Based on the age of anisotropic units, these deformations took place most likely during the Cadomian orogenic event and, subsequently, during Early Caledonian accretion at the EEC margin.

\section{Acknowledgements}

This work was financed by OPUS3 Grant No. DEC2012/05/B/ST10/00052 from NCN. This work was partially supported within statutory activities No $3841 / E-41 / S / 2016$ of the Ministry of Science and Higher Education of Poland. The GMT (Wessel and Smith 1995) and CWP/SU (Cohen and Stockwell 1997) packages were used for the preparation of the figures.

Open Access This article is distributed under the terms of the Creative Commons Attribution 4.0 International License (http:// creativecommons.org/licenses/by/4.0/), which permits unrestricted use, distribution, and reproduction in any medium, provided you give appropriate credit to the original author(s) and the source, provide a link to the Creative Commons license, and indicate if changes were made.

\section{REFERENCES}

Backus, G. E. (1965). Possible forms of seismic anisotropy of the uppermost mantle under oceans. Journal of Geophysical Research, 70, 3429-3439.

Belka, Z., Valverde-Vaquero, P., Dörr, W., Ahrendt, H., Wemmer, K., Franke, W., et al. (2002). Accretion of first Gondwanaderived terranes at the margin of Baltica. In J. A. Winchester, T. C. Pharaoh, \& J. Verniers (Eds.), Palaeozoic amalgamation of Central Europe (Vol. 201, pp. 19-36). London: Geological Society of London.

Buła, Z., \& Habryn, R. (2011). Precambrian and Palaeozoic basement of the Carpathian foredeep and the adjacent Outer Carpathians (SE Poland and western Ukraine). Annales Societatis Geologorum Poloniae, 81, 221-239.

Central Geological Database. (2016). Warszawa: Polish Geological Institute-National Research Institute. http://geoportal.pgi.gov.pl.

Christensen, N. I., \& Mooney, W. D. (1995). Seismic velocity structure and composition of the continental crust: A global review. Journal of Geophysical Research, 100, 9761-9788.

Cohen, J. K., \& Stockwell, J. W., Jr. (1997). CWP/SU: Seismic Unix Release 30: a free package for seismic research and processing. Golden: Center for Wave Phenomena, Colorado School of Mines.

Dadlez, R., Kowalczewski, Z., \& Znosko, J. (1994). Some key problems of the pre-Permian tectonics of Poland. Geological Quarterly, 38(2), 169-190.

Eberhart-Phillips, D., \& Mark Henderson, C. (2004). Including anisotropy in 3-D velocity inversion and application to Marlborough, New Zealand. Geophysical Journal International, 156, 237-254. doi:10.1111/j.1365-246X.2003.02044.x.

Efron, B. (1979). Bootstrap methods: Another look at the jackknife. The Annals of Statistics, 7, 1-26.

Enderle, U., Mechie, J., Sobolev, S., \& Fuchs, K. (1996). Seismic anisotropy within the uppermost mantle of southern Germany. Geophysical Journal International, 125, 747-767.

Gągała, Ł., Verges, J., Saura, E., Malata, T., Ringenbach, J.C., Werner, P., \& Krzywiec, P. (2012). Architecture and orogenic evolution of the northeastern Outer Carpathians from cross-section balancing and forward modeling. Tectonophysics, 532-535, 223-241.

Godfrey, J. N., Christensen, N. I., \& Okaya, D. A. (2000). Anisotropy of schists: Contribution of crustal anisotropy to active source seismic experiments and shear wave splitting observations. Journal of Geophysical Research, 105, 27991-28007.

Grad, M., Guterch, A., Keller, G. R., Janik, T., Hegedüs, E., Vozár, J., et al. (2006). Lithospheric structure beneath trans-Carpathian transect from Precambrian platform to Pannonian basin-CELEBRATION 2000 seismic profile CEL05. Journal of Geophysical Research, 111, B03301. doi:10.1029/ 2005 JB003647.

Guterch, A., Grad, M., \& Keller, G. R. (2001). Seismologists celebrate the new millennium with an experiment in Central Europe. EOS, Transactions American Geophysical Union 82(45), pp. 529, 534-535.

Guterch, A., Grad, M., Keller, G. R., Posgay, K., Vozár, J., Špičák, A., et al. (2003). CELEBRATION 2000 seismic experiment. Studia Geophysica et Geodaetica, 47, 659-669. 
Hearn, T. (1996). Anisotropic Pn tomography in the Western United States. Journal of Geophysical Research, 101, 8403-8414.

Jaworowski K., \& Sikorska M. (2006). Łysogóry Unit (Central Poland) versus East European Craton-application of sedimentological data from Cambrian siliciclastic association. Geological Quarterly, 50, 77-88.

Janik, T., Grad, M., Guterch, A., \& CELEBRATION 2000 Working Group. (2009). Lithospheric structure between the East European Craton and the Carpathians from the net of CELEBRATION 2000 seismic profiles in SE Poland. Geological Quarterly, 53(1), 141-158.

Johnston, J. E., \& Christensen, N. I. (1995). Seismic anisotropy of shales. Journal of Geophysical Research, 100, 5991-6003.

Karnkowski, P., \& Głowacki, E. (1961). O budowie geologicznej utworów podmioceńskich przedgórza Karpat środkowych. Geological Quarterly, 5(2), 372-419.

Krzywiec, P., Wysocka, A., Oszczypko, N., Mastalerz, K., Papiernik, B., Wróbel, G., Oszczypko-Clowes, M., Aleksandrowski, P., Madej, K., \& Kijewska, S. (2008). Evolution of the Miocene deposits of the Carpathian Foredeep in the vicinity of Rzeszów (the Sokołów-Smolarzyny 3D seismic survey area) (in Polish with English summary). Przeglad Geologiczny, 56, 232-244.

Kuo-Chen, H., Środa, P., Wu, F., Wang, C. Y., \& Kuo, Y. W. (2013). Seismic anisotropy of the upper crust in the mountain ranges of Taiwan from the TAIGER explosion experiment. Terrestrial, Atmospheric \& Oceanic Sciences, 24, 963-970. doi:10.3319/TAO.2013.07.30.01(T).

Malinowski, M., Żelaźniewicz, A., Grad, M., Guterch, A., Janik, T., \& CELEBRATION 2000 Working Group (2005). Seismic and geological structure of the crust in the transition from Baltica to Palaeozoic Europe in SE Poland-CELEBRATION 2000 experiment, profile CEL02. Tectonophysics, 401, 55-77.

Malinowski, M., Guterch, A., Narkiewicz, M., Probulski, J., Maksym, A., Majdański, M., et al. (2013). Deep seismic reflection profile in Central Europe reveals complex pattern of Paleozoic and Alpine accretion at the East European Craton margin. Geophysical Research Letters, 40, 3841-3846.

Malinowski, M., Guterch, A., Narkiewicz, M., Petecki, Z., Janik, T., Środa, P., Maksym, A., Probulski, J., Grad, M., Czuba, W., Gaczyński, E., Majdański, M., \& Jankowski, L. (2015). Geophysical constraints on the crustal structure of the East European Platform margin and its foreland based on the POLCRUST-01 deep reflection seismic profile. Tectonophysics, 653, 109-126. doi:10.1016/j.tecto.2015.03.029

Mizerski W. (1992). Tektonika utworów kambryjskich obszaru świętokrzyskiego. Przeglad Geologiczny, 40, 142-146.

Mizerski, W. (2004). Holy Cross Mountains in the Caledonian, Variscan and Alpine cycles-major problems, open questions. Przeglad Geologiczny, 52(8/2), 774-779.
Moryc W. \& Jachowicz M. (2000). Utwory prekambryjskie w rejonie Bochnia-Tarnów-Dębica. Przeglad Geologiczny, 48(7), 601-606.

Narkiewicz, M., Maksym, A., Malinowski, M., Grad, M., Guterch, A., Petecki, Z., Probulski, J., Janik, T., Majdański, M., Środa, P., Czuba, W., Gaczyński, E., \& Jankowski, L. (2015). Transcurrent nature of the Teisseyre-Tornquist Zone in Central Europe: results of the POLCRUST-01 deep reflection seismic profile. International Journal of Earth Sciences, 104, 775-796. doi:10. 1007/s00531-014-1116-4.

Pożaryski, W. (1990). The Middle Europe CaledonidesWrenching orogen composed of terranes. Geological Quarterly, 38, 1-9.

Raitt, R., Shor, J., Francis, T., \& Morris, G. (1969). Anisotropy of the Pacific upper mantle. Journal of Geophysical Research, 74, 3093-3109.

Růžek, B., Vavryčuk, V., Hrubcová, P., \& Zedník, J. (2003). Crustal anisotropy in the Bohemian Massif, Czech Republic: observations based on Central European Lithospheric Experiment Based on Refraction (CELEBRATION) 2000. Journal of Geophysical Research, 108(B8), 2392.

Song, L.-P., Koch, M., Koch, K., \& Schlittenhardt, J. (2001). Isotropic and anisotropic $\mathrm{Pn}$ velocity inversion of regional earthquake traveltimes underneath Germany. Geophysical Journal International, 146(3), 795-800.

Środa, P. (2006). Seismic anisotropy of the upper crust in southeastern Poland-effect of the compressional deformation at the EEC margin: Results of CELEBRATION 2000 seismic data inversion. Geophysical Research Letters, 33, L22302. doi:10. 1029/2006GL027701.

Środa, P., Czuba, W., Grad, M., Guterch, A., Tokarski, A. K., Janik, T., et al. (2006). Crustal and upper mantle structure of the Western Carpathians from CELEBRATION 2000 profiles CEL01 and CEL04: Seismic models and geological implications. Geophysical Journal International, 167, 737-760.

Stupnicka E. (1986). Charakterystyka strukturalna kambru zachodniej części antykliny chęcińskiej (Góry Świętokrzyskie). Biuletyn Geologiczny Uniwersytetu Warszawskiego, 30, 61-82.

Wessel, P., \& Smith, W. H. F. (1995). New version of Generic Mapping Tools released. Eos, Transactions American Geophysical Union, 76, 329.

Willmore, P. L., \& Bancroft, A. M. (1960). The time-term approach to refraction seismology. Geophysical Journal International RAS, 3, 419-432.

Żelaźniewicz, A., Buła, Z., Fanning, M., Seghedi, A., \& Żaba, J. (2009). More evidence on Neoproterozoic terranes in Southern Poland and southeastern Romania. Geological Quarterly, 58, 93-124. 